\title{
Estructura escatológica del sacramento de la reconciliación
}

Es común a todo sacramento una dimensión escatológica. Como evento salvifico, que relaciona existencialmente al hombre con Cristo, supone una aceptación en la fe de su persona y de la salvación definitiva, que él ha traído a los hombres. Cristo, sacramento primordial de salvación, presente en la Iglesia, sacramento universal de la misma salvación, realiza en los signos sacramentales el encuentro incorporador del hombre al reino, que él ha instaurado con su vida.

La unión resultante entre Cristo y el hombre, que recibe el sacramento, es la resurrección con Cristo, mediante la participación mistica en la vida divina, que introduce al cristiano en la eternidad misma de Dios. La muerte romperá los lazos, que aprisionan en la temporalidad esa vida eterna, y entonces el regenerado por el agua y el Espíritu experimentará en sí mismo la misma felicidad de Dios dentro de las limitaciones inherentes al ser creado.

Esta presencia de lo definitivo en la temporalidad del hombre se actualiza en todos los sacramentos, porque fruto de su eficiencia salvífica es la comunicación de la vida de la gracia. También el sacramento de la Reconciliación, por ser la revivificación del pecádor, comunica el Espíritu y participa de esta dimensión escatológica.

La pregunta concreta, al intentar determinar la estructura escatológica de la penitencia sacramental, es la siguiente: ¿Compete a este sacramento una dimensión escatológica propia en razón de su estructura especifica?

Tres son los puntos concretos, cuyo análisis puede ofrecer base sólida para responder a la pregunta propuesta: la situación del pecador bautizado, la conversión interior, y la reincorporación a la Iglesia.

1. La situación del pecador bautizado

Todo pecado es una opción libre y consciente del hombre, que 
rompe su relación vertical y amistosa con Dios en el orden sobrenatural. Es querer trazar su camino de salvación por rutas distintas a las marcadas por Dios. La búsqueda de la felicidad en independencia, y más aún en contra de la voluntad de Dios, es el móvil de toda acción pecaminosa. No es extraño que el pecado haya sido definido como un extravio, una equivocación, un error, que entraña al mismo tiempo una culpabilidad humana, que se traduce en los términos de rebelión, ingratitud, infidelidad, desobediencia.

En el transfondo de todo pecado late un sentimiento de culpabilidad, en virtud de la cual el hombre reconoce, que es objeto de la condenación de Dios, en cuanto se ha incapacitado para aceptarle. Es inherente al pecado cierto sello de imperdonabilidad, si se le considera desde el hombre. Salir del pecado supone volver a la amistad sobrenatural con Dios, para lo cual el hombre necesita el auxilio de ese Dios, a quien ha vuelto las espaldas. El hombre dejado a su propia suerte humana no puede de ninguna manera volver al plano sobrenatural de la vida de la gracia. Por su voluntad libre pudo caer en la sima, pero no puede salir de ella, si la mano todopoderosa de Dios no le ayuda a superar la miseria y muerte en que se encuentra.

El fino análisis, que hace el yavista de la situación de pecado en Adán, escenifica con acierto la tragedia interior del hombre, cuando toma conciencia de lo que supone haber roto la amistad con Dios. Adán ha desobedecido, rechazado su condición de creatura, y ha querido orientarse por caminos personales en contra de la prohibición taxativa de Yahvé. Busca ser como Dios, determinando po: sí mismo lo bueno y lo malo. Erigirse en árbitro del orden moral era la suprema manifestación del orgullo y soberbia humana.

Comida la fruta prohibida, Adán se siente condenado antes de que la voz de Dios le convoque a juicio. Su temor ante el Dios, que se pasea en el jardín a la hora de la brisa vespertina, y su escondimiento revelan su situación de lejanía de Dios y su incapacidad para la convivencia amistosa con él. La expulsión del paraiso no es más que la exteriorización de esa condenación interior, que Adán habia experimentado en su conciencia, al reconocer su desobediencia.

El hombre por el pecado se separa de Dios y se cierra a su amor. Desde la nueva situación ve de una manera distinta el rostro del Padre. No es Dios quien cambia sino el hombre. Si ahora huye es porque su conciencia le recrimina el mal que ha hecho. Sobre sí siente el peso de una condenación, que se prefigura en la huída espontánea del hombre. Se ha autocondenado. Al expulsar del cora- 
zón el amor, se le ha llenado de odio, temor y miedo. Adán en pecado no podía aguantar la proximidad del Dios creador.

Esta dimensión escatológica de la ofensa a Dios es participada también por el cristiano pecador. Pero su pecado reviste circunstancias muy peculiares, que agravan su situación en orden a la salvación definitiva. Si por la fe se apropió la salvación obrada en Cristo, por el pecado ha vuelto a las tinieblas de la muerte.

El bautismo sella una nueva relación vital entre el hombre y Dios. Creer es reconocer que Cristo es el único medio de salvación, porque no hay otro nombre, en el cual podamos salvarnos ${ }^{1}$, y aceptar a Cristo mediante una decisión libre, que comprometa al hombre en toda su radicalidad.

Esta opción supone una renuncia definitiva al pecado tan fuerte y absoluta como el muerto ha renunciado a la vida. El cristiano es un muerto al pecado para vivir la vida nueva, que en el bautismo se le ha comunicado.

Por el bautismo es un nuevo ser, un miembro de la nueva comunidad escatológica de salvación, anunciada por los profetas e instaurada en la predicación de Cristo. El movimiento de la fe no termina en Cristo, sino que se prolonga en su Iglesia, a la que se le ha dado ser sacramento universal de salvación. En virtud del contenido de su fe el cristiano, al convertirse, ha aceptado que para él fuera de la Iglesia no hay salvación y se adhiere a ella con todas sus fuerzas. Pertenecer a la Iglesia es formar parte de la comunidad de los salvados, que esperan la muerte como el momento supremo del paso al disfrute de la vida verdadera, poseída ya por el cristiano desde el momento de su inserción en el cuerpo místico de Cristo en la regeneración bautismal.

La predicación de Pablo es reiterativa y clara en este particular. El cristiano es un hombre, al que el amor misericordioso de Dios Padre llamó de la muerte, infligida por sus propios delitos, para vivificarle, resucitarle y sentarle en los cielos juntamente con Cristo. Por eso es un ser salvado ${ }^{2}$, cuya vida está escondida con Cristo en Dios. En su parusía los regenerados aparecerán gloriosos juntamente con él ${ }^{3}$. La vida terrena no es más que el tiempo de la espera.

El pecado del bautizado, aunque no sea contra fe, es una ruptura con Cristo. Quedan anuladas las relaciones vitales, que inau-

\footnotetext{
1. Hech 4,12.

2. Ef 2, 4-6.

3. Col 3, 1-4
} 
gurö el bautismo. La pertenencia a la Iglesia ha sido debilitada hasta el punto de convertir al pecador en un miembro muerto. Su situación es de condenación y él la siente como tal, porque se ve separado vitalmente del Cuerpo místico de Cristo, cuya pertenencia es para él condición indispensable para llegar a la vida eternamente verdadera.

Por el pecado el cristiano ha adelantado el juicio condenatorio de Dios en su propia existencia terrena. Para él valen las palabras de Jesús "el que no está conmigo está contra mi" ". "Porque la condenación está en que vino la luz al mundo, y los hombres amaron más las tinieblas que la luz; porque sus obras eran malas" ".

El cristiano pecador es un autocondenado. Dios se le ofrece siempre como amor en el Hijo. Es el hombre el que libremente puede aceptar o rechazar esa mano tendida de salvación. Su respuesta en el seguimiento de Cristo, bajo la acción de la gracia, determina su salvación o condenación. El hombre se salva ayudado por Dios, pero se condena por una acción totalmente suya. Sólo en el pecado no concurre Dios con la actividad humana. El rechazo de Cristo es la condenación que ratificará la muerte para siempre. La consecuencia del pecado es la condenación ${ }^{6}$.

Doblemente puede el cristiano renunciar a Cristo. O negando su fe, o no practicando deliberadamente los mandamienios. Por eso la muerte del pecado no es solamente la apostasia sino también la conculcación de la ley divina. Porque quien no guarda los mandamientos, no ama; y quien no ama no permanece en Cristo, ni Cristo en él ${ }^{7}$. Es un sarmiento seco, que no sirve para dar fruto. Será arrojado al fuego, donde se quemará ${ }^{8}$.

Esta concepción del pecado como autocondenación subyace a la predicación primitiva de la penitencia. Ya el Pastor de Hermas en su analogía de la Torre en construcción previene a los pecadores, para que vuelvan inmediatamente a la Iglesia. El pecado les ha situado fuera de la Torre y es necesario ser reincorporado en ella. De lo contrario, si la muerte les sorprende en ese estado, serán definitivamente excluidos de la vida. La reinserción en la Torre requiere como condición indispensable un periodo largo al cuidado del Pas-

\footnotetext{
4. $M t 12,30$.

5. Jn 3,19 .

6. Rom 6,$23 ; 8,6,13$.

7. Jn 14,$21 ; 15,10$.

8. Jn 15,6.
} 
tor de la Penitencia, que librará a los pecadores de convertirse en piedras reprobadas para siempre ${ }^{9}$.

Es fácil adivinar en la Teología del Pastor el principio general, repetido por los Padres, de que fuera de la Iglesia no hay salvación, como columna vertebral de su predicación penitencial. El apremio de hacer penitencia ante el inminente fin del mundo confirma esta tesis. No se trataba de una pertenencia juridica a la Iglesia. La insistencia en que quien haga penitencia vivirá, es porque considera, que la Iglesia es el medio único, en que los hombres llegan a participar en la vida divina.

"Anda, diles a todos, que hagan penitencia y vivirán para Dios (...). Cuantos de todo corazón hicieren penitencia y se purificaren de todas las maldades antes dichas y no vuelvan otra vez a añadir pecados a pecados, recibirán del señor curación de sus pecados pasados, a condición de que no duden sobre estos mandamientos, y vivirán para Dios. Todos aquellos, empero, me dijo, que añadan pecados a pecados y caminaren en las codicias de este siglo, se condenan a sí mismos a la muerte" ${ }^{10}$. Como se ve el pecado es causa de condenación, que solamente la penitencia en la Iglesia puede anular.

Tertuliano repite lo mismo en el libro De Paenitentia al inculcar la necesidad imperiosa de la exomológesis. Su dilema no deja lugar a dudas: o exomológesis, que reintegra al pecador a la comunidad de la Iglesia, o condenación. "Si no aceptas la exomológesis considera en tu corazón la gehenna, que te extinguirá la exomológesis, e imaginate antes la magnitud de las penas, para que no dudes en aceptar el remedio" "n.

Toda la praxis y Teologia penitencial de $\mathbf{S}$. Cipriano se asienta en la misma concepción. El cristiano pecador ha perdido el camino de la salvación y sólo con la penitencia, que le devuelve al seno de la Iglesia, puede evitarse "la espada espiritual y el juicio futuro de Cristo", porque los pecadores, que no se someten a los obispos y sacerdotes en el ejercicio de la penitencia pública, no tendrán posibilidad de vida y salvación ${ }^{12}$. Al que se le echa de la Iglesia por impenitente se le ha dado muerte con la espada espiritual, que ha sustituido a la que en la antigua ley castigaba con la muerte corporal. "Fuera de la Iglesia no puede tener vida, puesto que la casa

9. mERMAS, el Pastor. Vis. III, 6,1; 7,2.

10. HERMAS, el Pastor. Simil. VIII, 11,1,3.

11. TERTULIANO, De Paenitentia XII, 1.

12. CIPRIANO, Ep IV, 3,$2 ; 4,2$. 
de Dios es una sola y fuera de la Iglesia no hay salvación para nadie ${ }^{13}$. Por eso es deber del obispo procurar, que el pecador vuelva a la comunidad, previo el arrepentimiento y la exomológesis. Esta exigencia de pertenecer a la Iglesia llevó a conceder la reconciliación, aún antes de completar las obras penitenciales, cuando la inminencia de la muerte ponía en peligro la salvación eterna de los pecadores.

La disputa contra el rigorismo de Montano y Novaciano invocó, como argumento irrefragable, desde el lado ortodoxo la misma idea fundamental. No dar la reconciliación es crear en el pecador un clima de desesperación al privarle de la comunión con la Iglesia y en consecuencia de la posibilidad de la salvación.

La cita de autores testigos, que encuadran en esta misma concepción la teología del pecado como autocondenación, por haber cortado la unión vital con la Iglesia, medio único de salvación, se haria interminable y es por otra parte innecesaria. Quien peca en la Iglesia firma el decreto de su propia condenación, que permanece en vigor hasta que sea borrado por las lágrimas del dolor y la intervención de la Iglesia, que actúa con el poder de atar y desatar ${ }^{14}$.

\section{2. ㄴa conversión}

Gracia y pecado son los dos polos, en torno a los cuales gira toda la Historia de la Salvación. Dios intenta liberar al hombre de su pecado y el hombre, por una especie de fuerza interior moralmente irresistible, huye de su Creador y busca la felicidad por cuenta propia. Después del diluvio Yahvé constata desde lo alto, que es inútil castigar al hombre, porque desde la niñez son pecaminosas las tendencias de su corazón ${ }^{15}$.

A lo largo de la historia resuena ininterrumpidamente la voz de Dios, que llama al hombre para que conozca su error y vuelva libremente a la casa, de donde salió.

Israel es el escenario privilegiado de la lucha titánica y secular entre el amor de Dios, que no deja en su voluntad de salvar al hombre, y la fuerza del mal, introducida por el pecado del hombre, que inficciona el corazón de los mortales y la creación entera.

\footnotetext{
13. CIPRIANO, Ep. IV, 4,3 .

14. $M t 18,18$.

15. Gén 8,21 .

16. $M i q$ 6, 1-3.

17. Sof $2,4,15 ;$ Jer $25,30-3$. 8

18. Is 66,16; $\operatorname{Dan} 7,9-12 ; \operatorname{Sab} 4,20-5,23$.
} 
La voz de los profetas, como conciencia crítica del pueblo escogido, resonó potente en las filas de Israel, cuando, cerrados sus ojos por el desconocimiento del Dios de la Alianza, corría alocado en busca de otros dioses, que le dieran la verdadera felicidad. En su visión providencialista de la historia aquellos predicadores del A.T. interpretan los reveses políticos, los desastres militares o las calamidades climatológicas como un castigo de Dios, que descubre el estado de pecado, que invade al pueblo de Israel. Asi la historia se convierte en una llamada constante de Yahvé a la conversión. Es necesario abandonar la impiedad, dejar la idolatría y volver a la fidelidad de la Alianza practicando la justicia. No bastan los ritos de purificación, ni el humo de los sacrificios. La conversión requiere un corazón nuevo y nuevo amor.

En la abigarrada multitud de ideas y matices, que componer la Teología de la conversión predicada por los profetas, ocupa un puesto importante la evocación del juicio de Yahvé sobre los hombres. Israel es llamado a juicio ${ }^{16}$, y juntamente con él lo son también todos los pueblos de la tierra, a los que se ha extendido la iniquidad. Sus pecados les hacen reos de castigo. La copa de la ira de Yahvé se derramará sobre ellos y a espada serán pasadas todas las naciones, porque se han manchado con sus perversas acciones ${ }^{17}$. Un fuego devorador purificará ante el rostro de Dios a toda la humanidad pecadora ${ }^{18}$.

La invocación del dia de Yahvé es tema socorrido en esta predicación veterotestamentaria como un apremio a la converisión ${ }^{10}$. Las características trágicas, con que a veces se describe la naturaleza de ese día, pretenden crear en los pecadores la conciencia del mal, que han hecho, abriéndoles los ojos, para que consideren la dimensión escatológica de su rebeldía ante Yahvé ${ }^{20}$. El día de las tinieblas es el dia de la ira de Yahvé, que amenaza también a los paganos ${ }^{21}$. Solamente el arrepentido escapará de $s u$ furor ${ }^{22}$.

La invocación del juicio de Yahvé pretende primordial y únicamente sembrar el temor. En un examen de conciencia a la luz de la revelación busca, mediante el temor, una profundización en el conocimiento del pecado ${ }^{23}$. Dios es la misma santidad. Nada impuro puede acercarse a él, sin que sea fulminado por la pureza inmacu-

19. Sof 1,$18 ; \operatorname{Mal} 3,20 ; E \approx 7,6$.

20. Dan 1,26 .

21. Sal 1, 17-19; 56,8; 79,6.

22. Sal 30,$6 ; 65,3 ; 103,3$.

23. Is $54,4-6$. 
lada del que es tres veces santo ${ }^{24}$. Israel, sucio por sus adulterios e infidelidacles, siente sobre sí, conducido por la voz de los profetas, el juicio condenatorio de Dios, como una amenaza constante y terrible. Hay que desandar los caminos y volver desde lo más horido del yo pecador. No bastan los ritos de purificación, ni los sacrificios rituales. Sólo el que se arrepiente de veras, formará parte del Resto de Israel, portador de las promesas salvadoras. Sin conversión el juicio y la ira de Dios caerá implacable sobre la inmundicia de los corazones ${ }^{4}$.

La conversión es el comienzo de una vida nueva. Es necesario que la acción salvadora de Yahvé cambie el corazón de los hombres, quebrando su dureza y abriéndoles a la correspondencia en el amor ${ }^{26}$, y que los arrepentidos caminen detrás de Yahvé, buscando la justicia y el bien en la práctica de las buenas obras ${ }^{27}$. El convertido será un nuevo ser dentro de una nueva Alianza ${ }^{28}$. Por ese hombre nuevo suspira y suplica a Dios el salmista dolorido, cuando anhela una renovación total interior ${ }^{*}$.

Asi la conversión inaugura una era de paz y convivencia amorosa con Yahvé. La seguridad de su presencia entre los arrepentidos es una garantía de la salvación definitiva, porque ya se ha calmado la cólera de Yahvé. Su amor los fecundará como rocío, e Israel florecerá como el lirio, hundirá sus raíces como el Líbano, su eflorescencia será como la del olivo y su fragancia como la del Líbano ${ }^{30}$. Con estas metáforas cierra Oseas su mensaje de conversión, augurando la nueva época de la salvación, obrada por el amor misericordioso de Yahvé.

La voz de Juan, que ya en los albores del Reino, predica la conversión en el desierto no ha cambiado la temática fundamental de los profetas antiguos. Si ellos evocaban el juicio de Dios, que había de venir, Juan anuncia la presencia inminente de ese juicio en Aquel, que ya está para llegar. Con el bieldo en la mano para limpiar la era. Separará la paja del trigo. El grano será recogido en las paneras, mientras la paja se quemará en un fuego que nunca se apaga. Para Juan, el Bautista, el Reino de Jesús es el comienzo

\footnotetext{
24. Is 6, 3-5; $2 \operatorname{Sam} 6,7$.

25. Jer 4,4 .

26. $E \approx 11,17-21 ; 37,1-3$.

27. Am 5,4, 6-14; Miq 6,8

28. Jer 31,31 .

29. Sal 51, 12-13.

30. Os 14, 5-7.

31. $M t ~ 3,7-12 ; L c$ 3, 7-9.
} 
del juicio de Dios en la historia. La escatologia comienza. Los hombres serán discriminados. La conversión es el único medio de huir de la inminente ira de Dios ${ }^{\text {s2 }}$.

Una vez más la llamada a la conversión comienza por un reconocimiento de la situación trágica del pecador. Por su maldad se ha hecho paja en vez de trigo y será quemado inexorablemente. Jesús con su predicación y ofrecimiento de la salvación consumará esa separación, que el hombre ha hecho con su propia conducta. Asi debieron entenderlo los oyentes de Juan, cuando, compungidos en su corazón, preguntaban qué habían de hacer. La voz del Bautista había llevado a los pecadores a conocer su propia situación de pecado, evocando en ellos el temor de Dios como una consecuencia de sus malas obras.

El arrepentimiento es el único camino para una posible liberación. Doblemente la conversión reviste en esta predicación un carácter escatológico: brota de la dimensión escatológica del pecado, en cuanto condenación, y le introduce al hombre en el reino de la liberación, que se va a instaurar, por El que ya está llegando.

La predicación primitiva de Jesús es también una llamada a la conversión, que implica un juicio condenatorio de la humanidad. El Reino será para aquellos que lo acepten voluntariamente después de una metanoia. Los que no quieran convertirse quedarán fuera ${ }^{32}$. No creer en Cristo es condenarse ${ }^{3}$, y todo el que no se convierte, perecerá indefectiblemente ${ }^{\$ 4}$.

Según esta presentación sinóptica de la predicación de Jesús, el juicio de Dios se presencializa en la llegada del Reino. La proclamación del Evangelio fuevza al oyente a una opción por Jesús o en contra de él. Opción, que implica una salvación o condenación, porque quien no está con Cristo está contra él y quien le niega será negado.

Los sinópticos recurren no pocas veces como tema conversional al juicio futuro La constante llamada de atención ante la inesperada llegada del Hijo del hombre invita a los cristianos en multitud de pasajes del Evangelio a vivir alerta y en fidelidad. Es el tema, que ha inspirado las parábolas de la cizaña ${ }^{35}$, las virgenes prudentes ${ }^{\mathrm{s} 6}$, y otras, con las que intentaban crear o conservar en los

32. $M C$ 1,15.

33. Lc 12,8 .

34. LC 13, 1-5.

35. $M t 13,24$.

36. $M t ~ 25,1-13$. 
oyentes del evangelio el clima conversional. La descripción apocalíptica del juicio final reviste de una solemnidad sobrecogedora, en una línea veterotestamentaria, la seriedad del momento del encuentro con el Dios, que ha dado todo el poder de juzgar al Hijo ${ }^{37}$.

La relación juicio-conversión cristiana en su doble polaridad de alejamiento del pecado y seguimiento de Cristo la acentúa Mateo, al justificar la necesidad imperiosa de abrazarse con la cruz. De nada sirve ganar el mundo, si no se salva el alma. Hay que caminar detrás de Cristo con la propia cruz, porque vendrá un día en la gloria de su Padre a pagar a cada uno según su conducta ${ }^{38}$.

En espera de ese día Pablo siente la condenación o liberación en su propia conciencia. Teme y espera ${ }^{33}$. Si afronta la muerte con la esperanza del premio es, porque la mirada retrospectiva descubre una vida de servicio y fidelidad al Evangelio, que ha predicado ${ }^{\text {ta }}$. En su teología conversional no falta el tema del juicio como apremio a la conversión. La cólera de Dios se revela contra la humanidad, porque judios y griegos han pecado y están privados de la gloria de Dios ${ }^{41}$. Sus catálogos de pecados son taxativos: nadie que se deje llevar de las obras de la carne, podrá participar en el Reino de Dios ${ }^{42}$, porque el veredicto de Dios declara culpables de muerte a los que practican tales acciones pecaminosas ${ }^{43}$.

Esta dimensión condenatoria del pecado ês el transfondo, en que se recorta la llamada acuciante de Pablo, para combatir contra todos los enemigos, tomando las armas del guerrero cristiano ${ }^{44}$, porque el combate es decisivo, para poder seguir los imperativos de la vida según el Espíritu ${ }^{45}$.

Juan posee también como elemento esencial de su teología conversional la evocación del juicio futuro ${ }^{46}$. Resucitarán unos para la vida $y$ otros para la muerte.

Pero para Juan lo decisivo del juicio de Dios sobre el mundo más que un futuro es un presente. En la encarnación se presencializa el juicio escatológico. Cristo es là luz, que quieren aprisionar

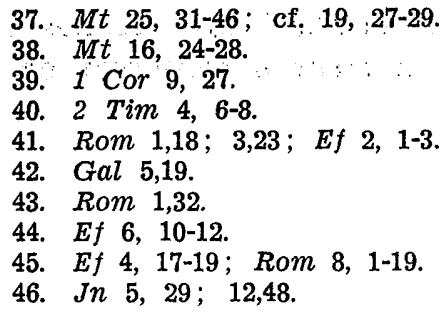


las tinieblas. Unos le aceptan y reciben como fruto de su fe la vida. En el fondo queda flotando la idea de que los que no crean en él, no participarán de los frutos de la encarnación. Todo el prólogo presenta de entrada la vida de Jesús como una discriminación entre los hombres.

Lucas había adelantado en la profecía de Simeón esta misma visión de la encarnación. Jesús está puesto para ruina y resurrección de Israel, porque hará que se manifiesten los secretos de los corazones. Las palabras del anciano vidente son una evocación dè juicio escatológico de Dios sobre los hombres, que de una manera especial se realizará en la pasión de Cristo.

Juan, en quien a todas luces parece inspirarse el tercer evangelista, proclama en el pórtico de la pasión, que el juicio del mundo va a verificarse en ella ${ }^{47}$. Desde la cruz lanzará la llamada amorosa que convoque hacia sí a todos los hombres ${ }^{48}$; y desde ella dará testimonio de que está con el Padre y que ha sido su enviado ${ }^{49}$.

En la conversación nocturna con Nicodemus, Juan explica con más detalle la realización de este juicio. Dios ama al mundo hásta darle a su propio Hijo, para que los hombres tengan vida. La encarnación no tiene por objeto condenar al mundo, sino salvarle. El Hijo clavado en la cruz, como la serpiente levantada por Moisés en el desierto para la curación del pueblo, es un signo revelador de ese designio amoroso del Padre, que quiere comunicar a los hombres, envenenados por el pecado, su propia vida divina, y en definitiva una llamada a lá conversión. Mirarán al que atravesaron ${ }^{50}$.

Pero la salvación requiere por parte del hombre la aceptación de ese ofrecimiento divino. Juan se complace en presentar a Jesús dirigiendo esta invitación a los hombres para que le sigan. Si alguno tiene sed, gritó Jesús en el templo, venga a mi y beba el que cree en mí, como dice la Escritura, de su seno correrán rios de agua viva ${ }^{51}$. "Yo soy la luz del mundo; el que me siga no caminará en la oscuridad, sino que tendrá la luz de la vida" 52 . A esta llamada no todos han querido corresponder. Muchos cerraron los ojos a la luz y así la salvación, ofrecida en la cruz, se ha convertido para ellos en condenación ${ }^{53}$.

\footnotetext{
47. Jn 12,31.

48. $J n 12,32$.

49. Jn $8,2,27$

50. $J n 19,37$.

51. $J n$ 7,37.

52. Jn 8,12.

53. Jn 3, 24-30.
} 
Juan concibe la predicación apostólica como la presentación de su experiencia personal en el seguimiento de Cristo. Anuncia 10 que vió, oyó y palpó del Verbo de la vida ${ }^{5}$. Para él Cristo es el único camino de salvación. Es la luz, la vida, la verdad, el camino. No hay otro fuera de él.

El hombre ha de aceptar a Cristo, entregarse a él, seguirle, si quiere salvarse. De lo contrario quedará sumido en las tinieblas de la muerte. Ante Cristo el hombre decide su propia salvación o condenación.

Cuanto acabamos de exponer no atañe únicamente a la primera conversión. Para Juan creer es no solamente aceptar que Jesús es el enviado del Padre, sino entregarse a él en el cumplimiento de sus mandamientos. También el que peca con el pecado, que no es de muerte, pierde la vida $\mathrm{y}$. sin ella no puede conseguir la salvación ${ }^{55}$. Odiar al hermano es permanecer en las tinieblas ${ }^{56}$. Quien peca es del diablo y quien no ama permanece en la muerte ${ }^{57}$. El imperativo cristiano de odiar al mundo nace del antagonismo entre sus concupiscencias y las exigencias de la vida en Cristo. "Si alguien ama al mundo, el amor del Padre no está en él" s8.

El juicio de Dios sobre los hombres no quedó aprisionado en la teología de Juan por las coordenadas de tiempo y lugar, que encuadran la muerte de Jesús en un determinado momento de la historia. El Paráclito, que él mismo enviará de cabe el Padre, será el continuador de su propia misión crítica. El Espiritu juzgará al mundo de su falta de fe en el seguimiento de Cristo ${ }^{52}$. Así el Espiritu, presente en la Iglesia y por medio de ella en el mundo, presencializa en cualquier momento de la historia el juicio de Dios.

Como espada de Damocles sobre la conciencia cristiana, el juicio de Dios es una invitación constante a la conversión. El cristiano no debe pecar, porque tiene en sí ya la vida eterna ${ }^{60}$, pero si sorprendido en el engaño peca, el recuerdo del veredicto de Dios le impulsa a la conversión mediante la vuelta a la vida.

Este breve recorrido por las líneas más generales de la Teología de la conversión han dejado patente su verdadera dimensión escatológica. La dialéctica de toda conversión es de muerte y vida, pe-

\footnotetext{
54. 1 Jn 1, 1-3.

55. 1 Jn 5,16 .

56. 1 Jn 2,9 .

57. $1 J n 3,8,14$.

58. 1 Jn 2,15.

59. Jn 16, 8-11.

60. $1 \mathrm{Jn} 3,9$.
} 
cado y liberación, condenación y salvación. La conversión supone en el arrepentido una conciencia de pecado, que implica una autocondenación, si el homrbe no desanda su camino. Ese primer sentimiento de dolor desde el abismo de su fracaso coloca al hombre en una perspectiva escatológica. Ha hecho real sobre si la palabra condenatoria, que el Hijo del hombre pronunciará sobre la humanidad no arrepentida al final de los tiempos ${ }^{61}$.

Este sentimiento de condenación no es percibido en el remordimiento cristiano en la negrura espesa del fracaso definitivo. En el horizonte brilla siempre la luz de una regeneración en la vuelta a la casa del Padre. Atraído por esa añoranza, el pecador. sale de su hondonada, ayudado de la gracia, para elevarse de nuevo a la dignidad perdida de hijo de Dios. Sabe que el dolor es el camino de la vida. En el encuentro sacramental con Cristo recibirá de nuevo el anillo de su filiación y el Espíritu, que le da derecho a ser heredero de Dios y coheredero de Cristo ${ }^{62}$.

El sacramento de la penitencia es en realidad el sacramento de la conversión cristiana. Todo él arranca del dolor del yo pecador, que vuelve en busca de lo perdido. En ese movimiento conversional, distinto de la conversión bautismal, aunque con muchos factores comunes, se encuentran los distintos elementos, que integran el signo sacramental. Porque la confesión de los pecados y la satisfacción de las obras penitenciales, al no ser más que la explicitación ante la Iglesia del dolor interior, participan de la misma dimensión escatológica de la conversión.

\section{La reconciliación eclesial}

Al desarrollar este tercer punto necesariamente hemos de hacer alusión, $\mathrm{y}$ aún repetir, ideas anteriormente expuestas. Resulta inevitable por la intima conexión entre pecado -conversión- reconciliación postbautismales. En el signo sacramental, integrado por los actos del penitente y la acción de la Iglesia, de tal manera se interrelacionan los diversos componentes, que se hace imposible hablar de uno de ellos sin entrar en el terreno de los otros dos.

Uno de los principios fundamentales de la Teologia penitencial es la concepción de la Iglesia como Cuerpo místico de Cristo y sacramento universal de salvación. Ya desde las cartas de Pablo; ser

61. $M t ~ 25,31-33$.

62. Rom 8, 14-16; Gal 3, 26-29; Didascalia II, 41,2; AMBROSIO, De Paenitentia, II, $\mathbf{3 , 1 8}$. 
cristiano conlleva: renuncia al reino de la muerte y purificación del pecado por el lavatorio bautismal, juntamente con la santificación de la regeneración, que le hace al bautizado partícipe de la vida divina ${ }^{63}$. La tensión del hombre nuevo será conservar esta antorcha encendida hasta el encuentro con Cristo en el momento de la muerte ${ }^{64}$.

Sobre la base de esta concepción se construye la Teologia del sacramento de la reconciliación y el mismo esquema litúrgico penitencial, por cuyo medio se concede el perdón de los pecados postbautismales.

El bautizado, que peca, rompe su comunicación con el cuerpo de Cristo. Se ha separado de la comunidad de los vivientes y es un miembro muerto. Su pecado tiene un doble efecto individual y social. Deshace la inserción del hombre en Cristo y mancha a la Jglesia.

Se abría el proceso penitencial con la excomunión del pecador por parte del obispo. El excomulgado quedaba oficialmente expulsado de la "ciudad de Dios edificada con piedras vivas" ${ }^{65}$, y "expuesto a los golpes de la ira de Dios" ${ }^{66}$. Hay en esta actuación eclesial una especie de anticipo del juicio escatológico. Los poderes de la Iglesia sobre los pecadores son una participación de los que el Padre ha confiado al Hijo, para que enjuicie todo pecado ${ }^{67}$. Con este poder juzgaba Pablo al incestuoso de Corinto entregándole a Satanás para la destrucción de la carne ${ }^{68}$.

Por este primer acto del proceso penitencial la Iglesia ha condenado en el nombre de Cristo al pecador, en tanto no vuelva a ser reincorporado a la vida, aue solamente ella posee. Los santos Padres consideraron al pecador muerto como Lázaro. Ha de volver a la vida por la voz de Cristo y ser desatado de su mortaja por las manos de la Iglesia. Bellamente desarrolla esta comparación S. Ambrosio: "Al ver el Señor Jesús el grave peso del pecador se echa a llorar; no resiste que llore la Iglesia sola; se compadece de su esposa amada y dice al difunto: Ven afuera, es decir, sal fuera el que yaces en las tinieblas de la conciencia y la inmundicia de tus pecados en cierta cárcel de reos, muestra tu pecado, para que seas justificado

63. Rom 6, 1-11.

64. Mt 25, 1-13.

65. ORIGENES, In Jer. fragm. 48.

66. In $P S \quad 37,1$.

67. $M t ~ 9,8 ; 19,28$.

68. 1 Cor 5, 3-5. 
(...). Se levanta el difunto, y manda que suelten los lazos del que todavía está en pecado, que se quite el velo de su cara, con el que ocultaba la verdad de la gracia, que habia recibido" ${ }^{69}$.

El pecador consideraba su situación peligrosa en orden a la salvación. La prisa de los apóstatas por ser reconciliados, cuando amenazaba el peligro de muerte, y la solicitud de los obispos por adelantar la reconciliación, aún sin la consumación de la exomológesis, demuestra que sobre el cristiano no reconciliado con la Iglesia, pesa el juicio condenatorio de Dios.

A lo largo del proceso penitencial el pecador experimentaba su muerte a la vida de la gracia, no sólo en las obras penitenciales, que mortificaban su cuerpo y daban muerte al yo pecador, sino en la prohibición de la eucaristia, expresión suma de la comunión con Cristo y garantia de inmortalidad.

La reconciliación era el último acto de la penitencia. La dura y laboriosa exomológesis garantizaba a la Iglesia la verdadera conversión del corazón. Mediante la imposición de las manos se transfundía al miembro muerto la vida, que por el pecado habia perdido. El Espíritu volvia a habitar en su alma, se le entregaba el anillo de su filiación y la garantía de la vida eterna ${ }^{70}$. Vuelto ya a los cuarteles de la Iglesia y recibida la paz, era de nuevo el pecador un cristiano en sentido pleno ${ }^{71}$, que podía participar en la eucaristía. "Jesús, comenta $\mathbf{S}$. Ambrosio, hizo revivir con solicitud al resucitado y alegre por la resurrección celebrada viene a la cena, que le preparó su Iglesia, y entre los invitados con Cristo se encuentra el que había sido un muerto" ${ }^{72}$. El reconciliado pidía esperar alegre la vuelta del Señor, porque su vida no era ya objeto de condenación.

El juicio de la Iglesia, como el del Padre en la muerte y resurrección de Cristo, ha sido liberador. Así lo expresa la fórmula del sacramentario mozarábico cuando dice: "para que una vez que ha conseguido la paz, merezca recibir la gracia de la inmortalidad" ${ }^{73}$, y la más explícita del Gelasiano en una de las oraciones de la $a b-$ solución, pronunciada por el obispo: "Perdona, Señor, al que se confiesa, para que por tu misericordia no caiga en las penas, que le amenazan, ni en la sentencia del juicio futuro" "4.

69. AMBROSIO, De Paenitentia II, 7, 57-58.

70. AMBROSIO, De Paenitentia, II, 3,18.

71. TERTULIANO, De Pudicitia X, 11; XIV, 17.

72. AMBROSIO, De Paenitentia II, 7,60.

73. FEROTIN, Liber ordinum, 98.

74. JUNGMANN, Die latinischen bussriten, 80. 
En la carne herida de Cristo quedó condenado el pecado ${ }^{75}$. Por la penitencia el cristiano se ha insertado en el dolor redentor de Cristo, porque "cuando padecemos en la satisfacción por los pecados nos conformamos a Cristo, que padeció por nuestros pecados, y tenemos la garantía ciertísima de que si padecemos con Cristo, seremos glorificados juntamente con él" ${ }^{76}$. Al someterse el pecador al juicio del Espíritu en la Iglesia, ha sentido la condenación en su propia carne pecadora, que resucita por los méritos de Crista a una nueva vida.

Esta realización pascual es muy peculiar del sacramento de la reconciliación. Si como el bautismo es una muerte al pecado y una resurrección en Cristo, una y otra se verifican con caracteres distintos en los dos sacramentos del perdón. En la conversión bautismal no entra como elemento integrador del signo una conversión dura y laboriosa, que hace morir en el dolor, libremente aceptado, al pecador. El juicio escatalógico sobre la humanidad, celebrado en la pasión gloriosa de Jesús, se verifica de distinta manera en los dos sacramentos. Por eso los Padres llamaron al perdón bautismal "áfesis" o perdón gratuito, mientras reservaron el nombre de "metanoia" al perdón penitencial, porque llevaba consigo una actitud de dolor, sacrificio y muerte en el cristiano pecador.

Al exponer la dimensión escatológica de la reconciliación eclesial hemos tenido presente de una manera preferencial la praxis penitencial de la Iglesia antigua. La mayor expresiviaad de su signo sacramental hace más inteligible el sentido escatológico del perdón. La separación del pecador como un condenado y su liberación, mediante la paz con la Iglesia, dramatizaban sensiblemente la trascendencia escatológica del pecado y de la reincorporación en la comunidad.

Pero es evidente, que todo lo dicho tiene la misma vigencia fundamental en el signo sacramental de la penitencia privada. La anticipación de la absolución al cumplimiento de las obras penitenciales o satisfacción y la menor expresividad del signo, por la desaparición del proceso de separación, no privan a la confesión de nuestros dias de los elementos esenciales del sacramento. También hoy la Iglesia responde a la acusación de los pecados con una condenación del pecador, al que impone unas condiciones para ser absuelto.

75. Rom 8,8: Col 2,13,14.

76. TRENTO [Conc. de], Ses. XIV, cap. 8. 
Sólo cuando el confesor tenga conciencia de su verdadera conversión y el penitente haya aceptado la satisfacción penitencial, podrá ser pronunciada la palabra de perdón. En caso contrario el pecador queda oficialmente excluido de la comunión y es en la comunidad un miembro muerto.

Sin duda la insistencia que hemos hecho en la dialéctica condenación-liberación del pecador como anticipo del juicio de Dios, puede parecer menos clara en la confesión de devoción, verdadera realización del sacramento. En ella el penitente no se acerca como un condenado, sino como quien, libre de pecado mortal, quiere someter al dinamismo del Espiritu la resistencia de la carne.

Sin embargo, a mi entender, también las confesiones de devoción jarticipan de la dimensión escatológica; tal y como ha sido propuesta. El penitente no es un miembro muerto, ni se siente condenado a la separación definitiva de Dios, pero sus pecados mortales ya pexdonados $y$ los veniales presentes le descubren, que no ha desaparecico en él del todo el reino de la muerte. Consta al mismo tiempo, que su vida no realiza perfectamente el ideal cristiano y es consciente de que nada impuro es admisible a los ojos de Dios. Teresa de Jesús, gran devota de la confesión frecuente, es un ejemplo de esta vivencia cristiana cuando dice: "Mira, Señor, lo que haces; no quites tan presto de la memoria la gravedad de mis culpas; y aunque no hayas olvidado de castigarlas, por lo menos acuérdate de poner tasa en los beneficios que me has de hacer. No sea tu amor tan grande, Rey Eterno, que te fuerce a dar a una monja pecadora y pésima unas margaritas tan preciosas, porque de aqui adelante no dé ocasión de tenerlas en poco" "7.

Este doble factor: el desajuste entre la vida y el compromiso; y el sentimiento de que hay en ser regenerado una falta de correspondencia al amor de Dios, crea en la conciencia cristiana un sentimiento de dolor y conversión. Sus imperfecciones serán juzgadas y condenadas en el último día. El someterse al juicio de la Iglesia abriga la certeza de adelantar ese juicio, que también para él es liberador. La reconciliación con la Iglesia le garantiza su purificación y le ayuda a conformar su vida a la de Cristo, en la espera de su vuelta ${ }^{78}$.

77. TERESA [Sta.], Obras completas. B.A.C., (Madrid 1958) 910.

78. Mystici Corporis: DS 3818; Novus Ordo Penitentiae, núm. $7 \mathrm{~b}$. 


\section{CONCLUSION}

La dimensión escatológica del sacramento de la penitencia es una realidad que pervade todo el signo sacramental. Lo escatológico, lo definitivo, seguir o no a Cristo, vivir o no libre y conscientemente en su Iglesia, es lo que estructura todo el signo, a través de los actos del penitente, que forman parte de él. Porque el pecado es una autocondenación; el cristiano se vuelve hacia Dios en espera de restablecer una amistad perdida y camina a su encuentro en la Iglesia, sacramento universal de salvación, porque en ella está el Espiritu y la vida ${ }^{79}$. La Iglesia le acoge de nuevo en su regazo con la certeza de hacerle objeto en su acción reconciliatoria del juicio liberador del Padre en la muerte y resurrección de su Hijo. "Cuando el confesor recibe al pecador penitente y le lleva a la luz de la verdad, realiza funciones paternas, al revelar a los hombres el corazón del Padre y reproducir la imagen de Cristo Pastor. Acuérdese, por lo tanto, que se le ha confiado la función de Cristo, que consumó misericordiosamente la obra de la redención para salvar a los hombres, y está presente con su virtualidad en los sacramentos" ${ }^{80}$.

Alejandro Martínez Sierra, S.J. Universidad Pontificia de Comillas MADRID

79. IRENEO, Adversus haereses III, 24,1.

80. Novus Ordo Penitentiae, núm. 10c; cf. TRENTO [Conc. de], Ses. XIV, cap. 6. 